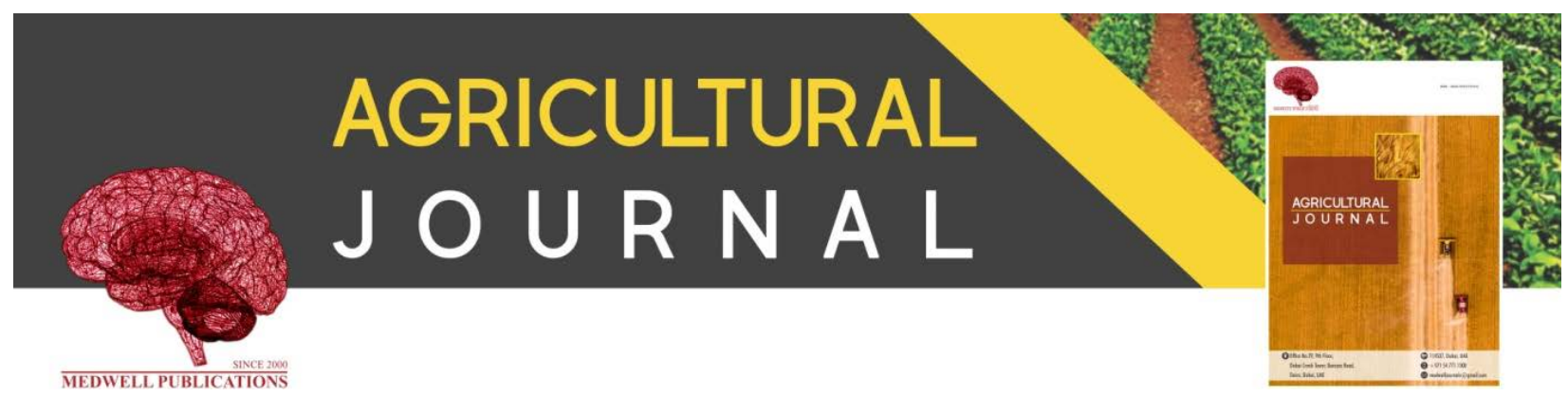

\title{
Measuring the Amount of Environmental Pollution Resulting from Nuclear Radiation in the Soil of the City of Hilla
}

\author{
${ }^{1}$ Ahmed Y. Ali, ${ }^{1}$ Hussain A. Laken and ${ }^{2}$ Inaam H. Kadhim \\ ${ }^{1}$ Ministry of Education, Baghdad, Iraq \\ ${ }^{2}$ Department of Physics, College of Education for Pure Sciences, University of Babylon, \\ Hillah, Iraq
}

Key words: $\mathrm{NaI}(\mathrm{Tl})$ detector, natural radioactivity, the soil, Hilla, Babil governorate, radioactivity

\section{Corresponding Author:}

Ahmed Y. Ali

Ministry of Education, Baghdad, Iraq

Page No.: 20-25

Volume: 15, Issue 2, 2020

ISSN: 1816-9155

Agricultural Journal

Copy Right: Medwell Publications
Abstract: The study was conducted in Babil governorate and for ten different sites using the Sodium Chloride (TI) sodium oxidation detector and then calculating the content of the samples of Potassium ${ }^{40} \mathrm{~K}$, Uranium ${ }^{238} \mathrm{U}$ and Thurium ${ }^{238} \mathrm{Th}$. It was found that the radioactivity of Potassium ${ }^{40} \mathrm{~K}$ in the studied models ranged from (2067.3-623), ${ }^{238} \mathrm{U}$ (136.5-64) Bq kg ${ }^{-1}$, Thorium ${ }^{232} \mathrm{Th}$, (244-12.29) $\mathrm{Bq} \mathrm{kg}^{-1}$, respectively. Therefore, it was found that the radiation levels of the studied models are within the limits allowed globally.

\section{INTRODUCTION}

Natural radioactivity is widespread in the earth and is present in a different environment geological formations in the rocks and plants and soil water, air, building materials and food. The natural radioactivity of environmental studies, so not only for the impact of radiation, necessary but have a great interest and importance in health physics as well as their ability. Environmental radioactivity depends on the local and geographic geological conditions. Notes at different levels in each region of the world and the rate of natural gamma dose is an important factor in the average dose population receives. For many researchers around the world, the natural rate of radioactivity in soil measurement is of great importance which has led to national surveys around the world in the last two years decades. With the time spent for natural radioactivity in the soil is very important to determine the amount of change in natural background activity (Jassim et al., 2016). In nature, all things seek to shift from the state of zero stability to the most stable state possible and the nuclei of the atoms are no different they transform from unstable atoms into a more stable nucleus through the process of nuclear degeneration that is known as radiological pastime. There are each radiant and irradiant atoms. Radiant atoms are divided into kinds. The unstable that occurs naturally and shows the natural radiological activity and the unstable that are produced in the labs through nuclear reactions and shows the industrial radiation activity (Hasan et al., 2017).

Natural radioactivity is as a result of the presence of natural radioactive matter going on radioactive remember (NORM) inside the surroundings. Examples of herbal radionuclides encompass isotopes of potassium $\left({ }^{40} \mathrm{~K}\right)$, Uranium $\left({ }^{238} \mathrm{U}\right.$ and its decay collection) and Thorium ( ${ }^{232} \mathrm{Th}$ and its decay collection). In addition to being lengthy-lived (inside the order of 1010 years) those radionuclides are normally found in air, soil and water in distinct quantities and tiers of interest (Abojassim et al., 2014a). Radon is a chemical detail with image $\mathrm{Rn}$ and atomic wide variety 86 . It is a radioactive, colorless, odorless, tasteless noble gasoline, happening clearly as an oblique decay fabricated from uranium or thorium. Its most stable isotope, ${ }^{222} \mathrm{Rn}$, Radon is one of the densest substances that remains a gas under normal conditions. It is likewise the most effective gasoline below regular 
Agric. J., 15 (2): 20-25, 2020

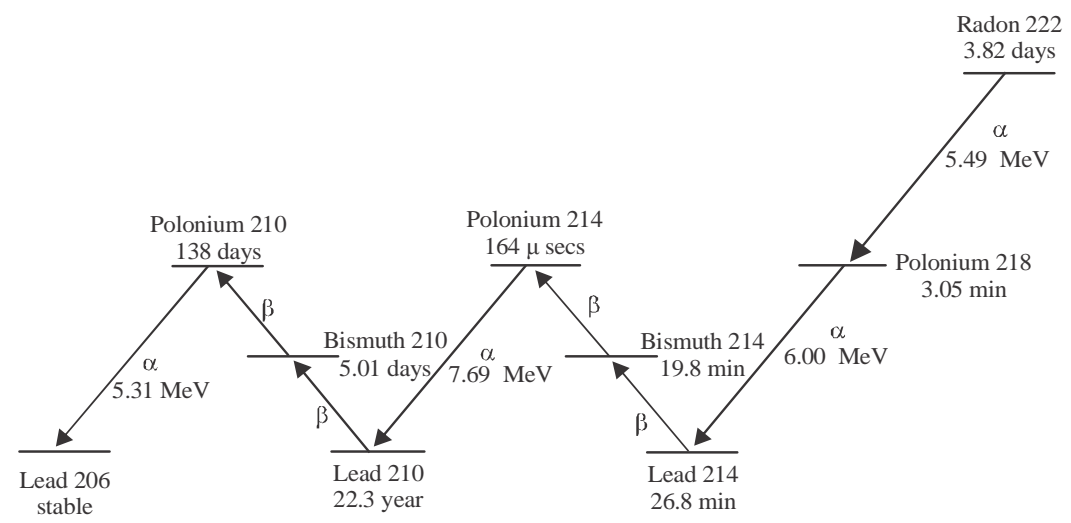

Fig. 1: Radon decay chain

Table 1: The main characteristics of the four chains

\begin{tabular}{lcllc}
\hline Radioactive gas & Longer half (year) & Last item & First item & The name of the string \\
\hline The Huron-220 & $1.4 \times 109$ & Lead-208 & Thorium-232 & Thorium 4n \\
LaGas in this series & $2.14 \times 106$ & Bismuth-209 & Plutonium-241 & Neptunium 4n+1 \\
Radon-222 & $4.5 \times 109$ & Lead-206 & Uranium-238 & Uranium 4n+2 \\
Actinon-219 & $7.1 \times 108$ & Lead & Uranium-235 & Actinium 3+4n \\
\hline
\end{tabular}

situations that simplest has radioactive isotopes and is taken into consideration a fitness danger because of its radioactivity. Intense radioactivity has also hindered chemical studies of radon and only a few compounds are known (Al-Jnaby, 2016).

Radon isotopes are vital chemically inert radioactive gases that arise inside the surroundings due to the heavy factors decay of radioactive factors in soil and minerals. Thoron $\left({ }^{220} \mathrm{Rn}\right)$ is one of three naturally occurring radon isotopes which results from the decay of Thorium $\left({ }^{232} \mathrm{Th}\right)$ series. This isotope equal $55 \mathrm{sec}$ half-life. The $\left({ }^{220} \mathrm{Rn}\right)$ concentration is so irregular, so, it is difficult to get a representative in inside environments, the air mix time is commonly much larger than the half-life of $\left({ }^{220} \mathrm{Rn}\right)$, so, it is difficult to get a representative value of indoor $\left({ }^{220} \mathrm{Rn}\right)$ concentrations. Moreover $\left({ }^{222} \mathrm{Rn}\right)$ progeny is much more important than $\left({ }^{220} \mathrm{Rn}\right)$. Therefore, it is desirable to know the concentrations of $\left({ }^{222} \mathrm{Rn}\right)$ progeny. Thoron can still be a hazard, since, its Progeny $\left({ }^{212} \mathrm{~Pb}\right)$ with a half-life of $10.6 \mathrm{~h}$ can accumulate to significant levels in breath able air (Abojassim et al., 2014b) (Fig. 1).

Radium and its closing precursor uranium within the floor are the supply of radon an $\alpha$-radioactive inert gasoline. As an inert fuel and having a sufficiently long lifetime (3.8 days) it can move freely through the materials like soil, Sand, rock and so, forth. Short lived radon progenies had been hooked up as causative marketers of lung most cancers. Radon appears when Radium ( $\left.{ }^{226} \mathrm{Ra}\right)-238 \mathrm{U}$-family division product-splits up. In many nations the maximum essential supply of radon is the floor but it's miles viable that radon's volumetric hobby interior is decided via. constructing substances, water-supply (Obaid et al., 2015). Radon is soluble in water if high concentrations are found in drinking water the rate of exposure may be also important (Embaby et al., 2016) (Table 1).

Naturally occurring radionuclides enter the human body mainly by inhalation of radon and thoron gases and their decay products by ingestion of primordial radionuclides and their progeny, ${ }^{40} \mathrm{~K}$ and the ${ }^{238} \mathrm{U}$ and ${ }^{232}$ Th series. The ingested radionuclides could be concentrated in certain parts of the body for example ${ }^{238} \mathrm{U}$ accumulated in human kidney and lungs, ${ }^{232} \mathrm{Th}$ in liver, skeleton tissue and lungs and ${ }^{40} \mathrm{~K}$ in muscles (Adeniji et al., 2013). Radon concentrations in soil gas within few meters of the surface of the ground are clearly important in determining radon rates of entry into pore spaces and subsequently into the surroundings and it's rely on the radium awareness inside the bedrock and at the permeability of the soil. Since, radon is a fuel it can get away into the air from the fabric wherein it's far fashioned and for the reason that uranium and radium arise extensively in soil and water, radon gasoline is ubiquitous-exterior in addition to interior, the air that we inhale consists of radon (Hameed, 2015).

The risk due to exposure of the ingested radon with intake of the water is smaller than the risk of developing lung cancer from inhaled radon released to air from exhalation from the same water. Because certain building materials with high concentrations of radium, domestic water with high concentrations of radon and their utilitarian purposes and even the type of soil can make major contributions to indoor radon exposure (Ravikumar and Somashekar, 2014). The main source of 
the indoor thoron concentration is the surrounding building material. In the traditional dwellings, this is the bare soil floor, either soil in cave dwellings or unburned adobe bricks and un plastered stone in aboveground dwellings. It is thought that the inhalation dose to the people from thoron and its progeny is negligible despite the fact that latest research in many nations have discovered that this will now not be totally accurate (Al-Hamidawi, 2015).

\section{MATERIALS AND METHODS}

The aim of study: The objective of this research is to measure and study the levels of radiation activity and environmental pollution in different samples from different districts in Hilla city, Babil province because of its effect on human health by measuring the specific efficacy of potassium ${ }^{40} \mathrm{~K}$, Uranium ${ }^{238} \mathrm{U}$ and Thorium ${ }^{232} \mathrm{Th}$ and comparing it with the level of global radiation activity.

Area of study: Selected locations from the most sacred areas of Hilla (an Iraqi city in Babil governorate) with four samples per area, bringing the total number of samples to twenty. It is located about $100 \mathrm{~km}$ South of Baghdad (32 $\left.32^{\prime} 50^{\prime \prime N}, 44^{\circ} 14^{\prime} 40^{\prime \prime} \mathrm{E}\right)$ is located on both sides of the River Hilla (branch of the Euphrates River) at the latitude (29'32 North) North, longitude (26'44 East) as shown in Fig. 2.

Experimental details: The specific radiation activity of gamma rays to measure based on the high penetration strength using counting and electronic analysis used in the detection consisting of an array of detectors of nuclear

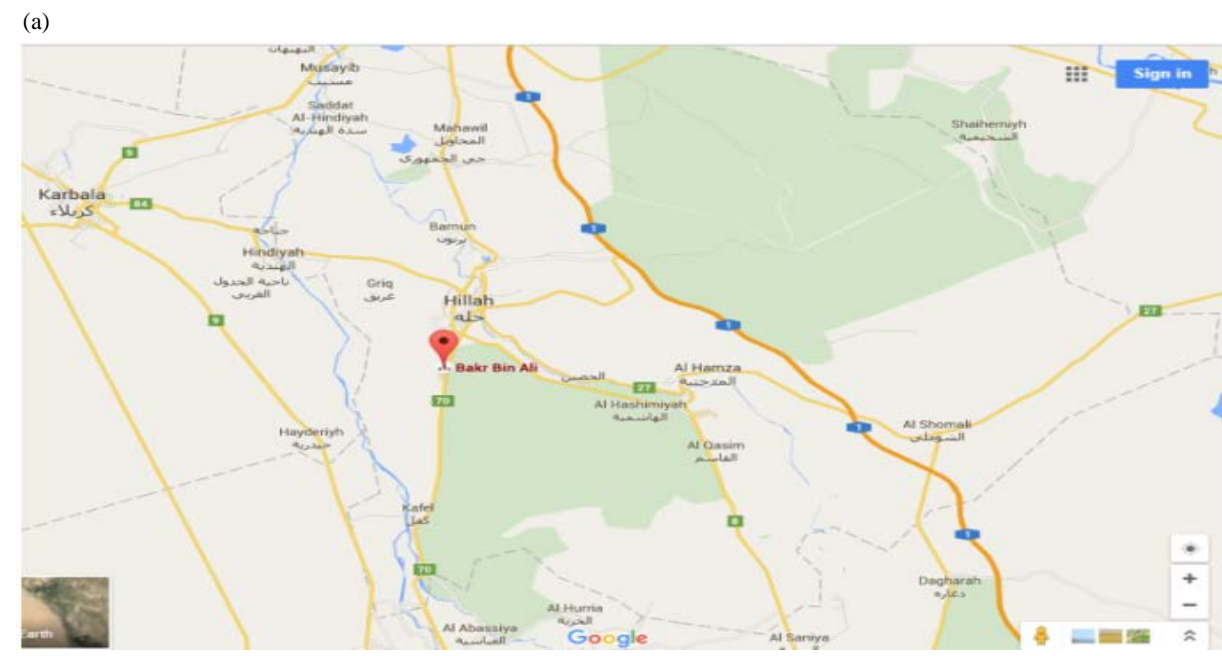

(b)

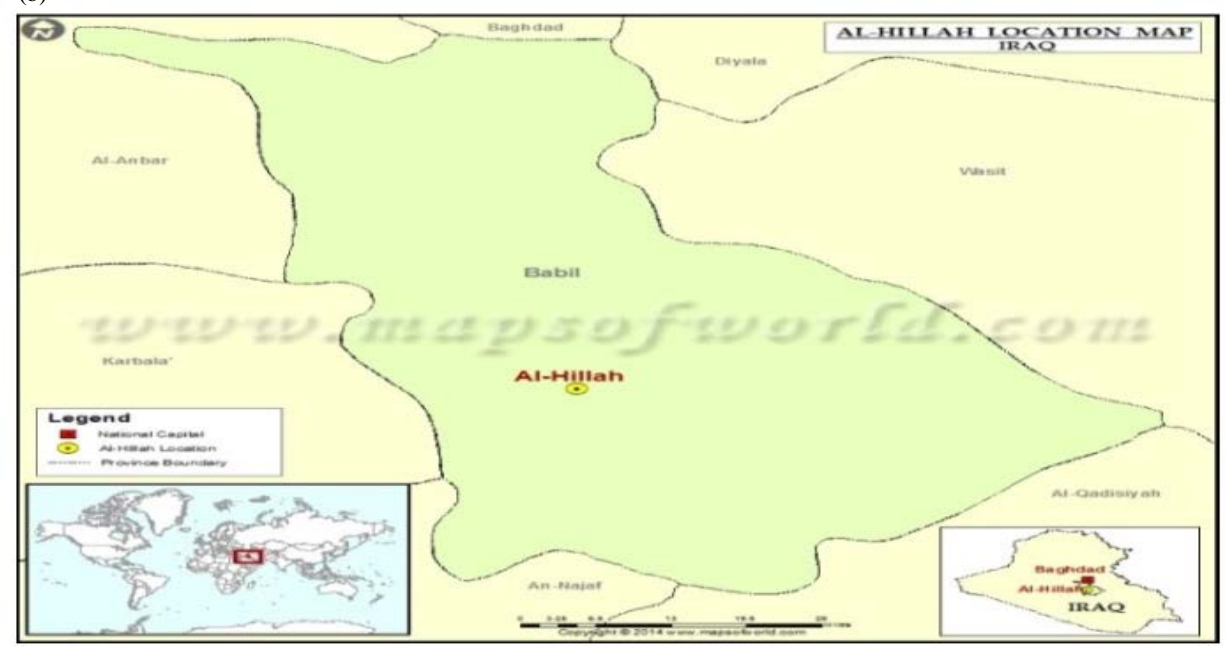

Fig. 2(a, b): Geological map of the region selected in the research 
radiation sodium iodide system Restaurant thallium $\mathrm{NaI}(\mathrm{TI})$ and the supplier of the company (Alpha Spectra, Inc.-12I12/3) provider is a Multi-Channel Analyzer (MCA) (ORTEC -Digi Base) that contains a 4096 channel connecting unit called ADC (Analog to digital convertor) (Embaby et al., 2016) helps the analyst to convert the next pulse into digital numbers, though nuclear measurements and analysis done by a computer software called (MAESTRO-32).

The radioactivity of radionuclide's emitting gamma rays to measure by reference to the power of the high penetration of gamma rays in the material using counting and electronic analysis used in the detection consisting of an array of detectors of nuclear radiation sodium iodide system Restaurant thallium NaI (TI) (“3×3”) and the supplier of the company (Alpha Spectra, Inc.-12I12/3) provider is a Multi-Channel Analyzer (MCA) (ORTEC-Digi Base) that contains a 4096 channel connecting unit called ADC (Analog to Digital Convertor) helps the analyst to convert the next pulse into digital numbers, though nuclear measurements and analysis done by a computer Software called (MAESTRO-32) as shown in Fig. 2a, b.

\section{RESULTS AND DISCUSSION}

Detection system and nuclear analysis used NaI (TI): To study the natural radioactivity of the gamma-emitting nuclides such as ${ }^{238} \mathrm{U},{ }^{232} \mathrm{Th}$ and ${ }^{40} \mathrm{~K}$ as well as to detect nuclear radiation, the system has been used detection and analysis of sodium iodide NaI (TI) for its large efficiency and for the atomic number of the thallium and iodine components. This system is equipped with its partner (Ortec) and is made up of a multi-channel analyst with (4096) channel that connects to a unit called (A.D.C.) Through software, nuclear measurements are performed and analyzed and this software is installed on the computer named Maestro-32 in the research lab. Figure 3 illustrates the sodium iodide detector. Using the following radioactive sources (C0-60, Ba-133,co-57, Cs-137, Na-22, Mn-54, Cd-109) and the cards go between (1332.5-88) Kev to calibrate the measurement system.

After the collection and configuration of the models and calibration of the detection and measurement system and recording the spectrum of the background radiation samples. Each prepared soil container was placed on a shielded, NaI (Tl) Scintillator, detector " $3 \times 3$ ” and by 1.8 $\mathrm{KeV}$ energy resolution (FWHM) at the $1.33 \mathrm{MeV}$ reference transition of $60 \mathrm{Co}$. The samples were measured for a counting time of $18000 \mathrm{sec}$ and samples were mass (1 kg) to obtain a statistically small error (3-5\%) for the $\gamma$-ray peaks of interest. Further details of the high-resolution spectrometry system as well as of the data analysis technique are presented elsewhere. Following the
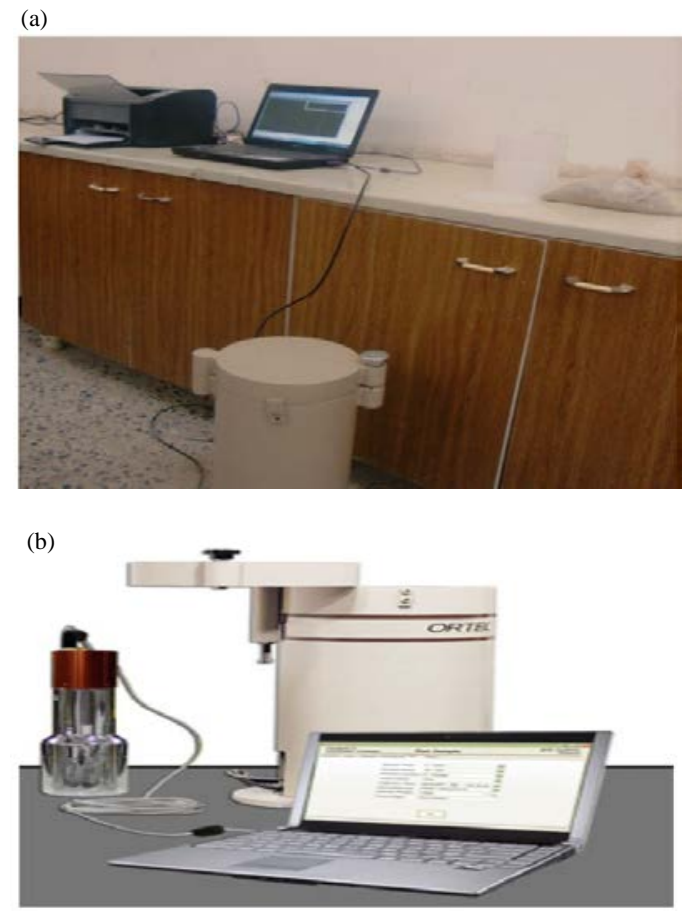

Fig. 3(a, b): The gamma spectroscopy detection system used in the present study

spectrum analysis, count rates for each detected photo peak and activity concentration in units of $\mathrm{Bq} \mathrm{kg}^{-1}$ for each of the detected nuclides are calculated. The total uncertainty of the radioactivity measurements which is also applicable to the calculated gamma dose and effective dose rates was typically in the range 3-10\%. It has been calculated by taking into consideration the counting statistical error (3\%) and other weighted systematic errors that mainly include the uncertainty in the efficiency calibration (0.5-8\%). Depending on the peak background of the measured spectra, the Minimum Detectable Activity (MDA) was calculated to be $1.0 \times 10-2 \mathrm{~Bq} \mathrm{~kg}^{-1}$ for both ${ }^{232} \mathrm{Th}$ and ${ }^{238} \mathrm{U}$ and $4.0 \times 10-2 \mathrm{~Bq} \mathrm{~kg}^{-1}$ for ${ }^{40} \mathrm{~K}$. In this study, soil samples were selected from different parts of the city of HillaBabel. Soil samples were tested by: Al-Hussein neighborhood, Al-Zahra neighborhood, Al-Jama’a district, in Sinjar area, Al-Tahmaziyah, Zogheib 1, Zogheib 2, Raghilah 1 and Ragilla 2, 10 toxicity (Table 2 and 3).

The radioactive samples test: The radiation Background (BG) were calculated to sub it from the energy spectrum for the studied samples using the following equation:

$$
\mathrm{BG}(\mathrm{Bq})=\frac{\text { Area }}{\mathrm{I}_{\gamma} \% \zeta \% \mathrm{~T}}
$$


Agric. J., 15 (2): 20-25, 2020

Table 2: Nucleic acids based on research, energy, associated intensity and efficiency

\begin{tabular}{lccc}
\hline Efficiency (\%) & Intensity (\%) & Energy elements & Radioactive elements \\
\hline 0.000918 & 0.11 & 1460 & $\mathrm{~K}^{40}$ \\
0.00504 & 0.47 & 609 & $\mathrm{Bi}^{214}$ \\
0.00866 & 0.15 & 338 & $\mathrm{Th}^{232}$ \\
\hline
\end{tabular}

Table 3: Specific quality of uranium, potassium and thorium for samples taken from the surface

\begin{tabular}{|c|c|c|c|c|c|c|}
\hline \multirow[b]{2}{*}{ Samples } & \multicolumn{2}{|l|}{$\left(\mathrm{Th}^{232}\right)^{234} \mathrm{Th}$} & \multicolumn{2}{|l|}{$\left(\mathrm{Bi}^{214}\right)^{238} \mathrm{U}$} & \multicolumn{2}{|l|}{${ }^{40} \mathrm{~K}$} \\
\hline & $\begin{array}{c}\text { Effectiveness } \\
(\%)\end{array}$ & $\begin{array}{c}\text { Area under } \\
\text { curved }\end{array}$ & $\begin{array}{c}\text { Effectiveness } \\
(\%)\end{array}$ & $\begin{array}{l}\text { Area under } \\
\text { curved }\end{array}$ & $\begin{array}{c}\text { Effectiveness } \\
(\%)\end{array}$ & $\begin{array}{c}\text { Area under } \\
\text { curved }\end{array}$ \\
\hline 1 & 144 & 3378 & 86.00 & 3691 & 623.0 & 1134 \\
\hline 2 & 117 & 4146 & 76.00 & 3260 & 1173.0 & 2133 \\
\hline 3 & 192 & 4506 & 93.00 & 3970 & 1364.0 & 2481 \\
\hline 4 & 244 & 5708 & 64.00 & 2748 & 1413.0 & 2570 \\
\hline 5 & 198 & 4653 & 65.00 & 2793 & 2081.0 & 3783 \\
\hline 6 & 16.1 & 334 & 115.94 & 1703 & 1986.9 & 21230 \\
\hline 7 & 12.82 & 266 & 134.05 & 1969 & 1995.8 & 21325 \\
\hline 8 & 12.29 & 255 & 85.98 & 1263 & 1797.6 & 19208 \\
\hline 9 & 38.91 & 807 & 119.75 & 1759 & 2066.01 & 22075 \\
\hline 10 & 27.39 & 568 & 136.50 & 2005 & 2067.3 & 22089 \\
\hline
\end{tabular}

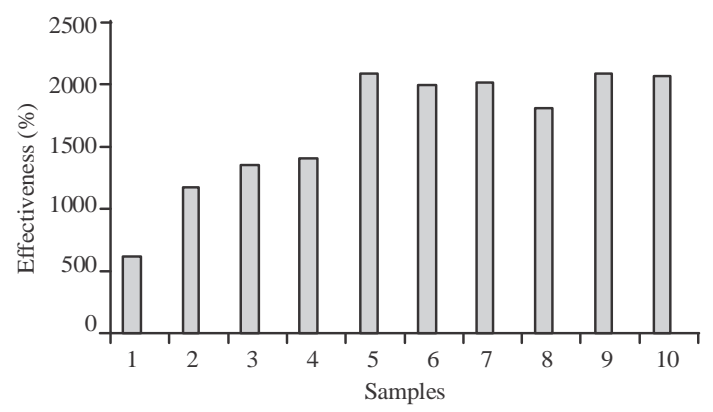

Fig. 4: The concentration of potassium-40 for selected samples

The specials radioactivity was calculated for each sample with time of 18000 sec by using equation and tabulated in Table:

$$
\text { Specific acticity }\left(\mathrm{Bq} \mathrm{kg}^{-1}\right)=\frac{\frac{\text { Area }}{\mathrm{T}}-\mathrm{BG}}{\mathrm{I}_{\gamma} \% \zeta \mathrm{m}}
$$

Where:

Area : Net area under the photo peak position

m : Mass of sample unit $(\mathrm{kg})$

In this study, the concentration of the effectiveness of radioactive elements was measured in the soil surface samples of various sites of Hilla city, the center of Babil province which focused on the various districts and districts of the province whose soil varied between sandy soils and clay soils.

The highest value of ${ }^{40} \mathrm{~K}$ was $2067.3 \mathrm{~Bq} \mathrm{~kg}^{-1}$ in model (10) which represents the soil of the eucalyptus region while the lowest value of the specific effect (623 Bq kg-1) in model (1) (Fig. 4).

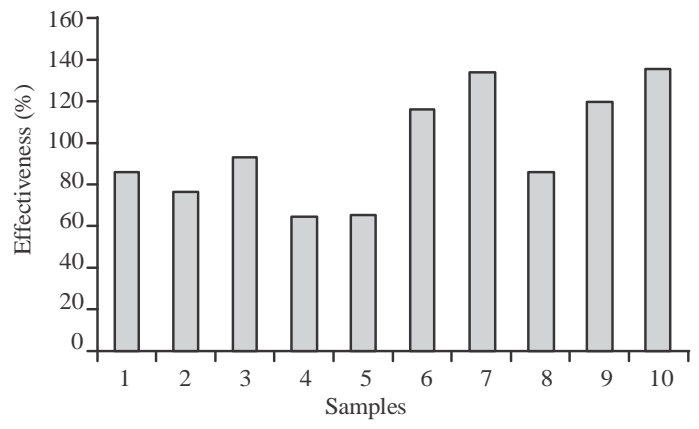

Fig. 5: The concentration of uranium-238 for selected samples

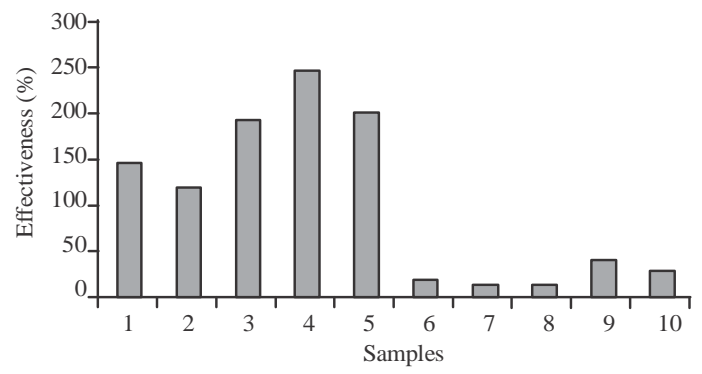

Fig. 6: The concentration of uranium-238 for selected samples

The highest value of ${ }^{238} \mathrm{U}$ was found to be (136.5 Bq kg ${ }^{-1}$ ) in model (10) which represents the living area of the university while the lowest value of the activity (64 Bq kg-1) in model (4) which represents the soil of Sinjar (Fig. 5).

The highest value of the ${ }^{332} \mathrm{Th}$ thorium was found in the soil model (4) with a value of $244 \mathrm{~Bq} \mathrm{~kg}^{-1}$ while the lowest value of the specific effect in model (8) which represents the soil (12.29 $\left.\mathrm{Bq} \mathrm{kg}^{-1}\right)$ (Fig. 6). 


\section{CONCLUSION}

The elements detected in the studied samples are among the series of Uranium, Thorium and Potassium which have a small counting rate, indicating that the $\mathrm{Bq} \mathrm{kg}{ }^{-1}$ is very low compared to the permissible limit. Therefore, these few percentages indicate that the studied areas of Babil governorate are free of nuclear radiation from depleted uranium.

\section{REFERENCES}

Abojassim, A.A., H.H. Al-Gazaly and S.H. Kadhim, 2014a. ${ }^{238} \mathrm{U},{ }^{232} \mathrm{Th}$ and ${ }^{40} \mathrm{~K}$ in wheat flour samples of Iraq markets. Ukrainian Food J., 3: 333-340.

Abojassim A.A., H.H. Abd, D.N. Hamed and A.A. Abdullah, 2014b. Study of radioactivity levels in detergent powders samples by gamma spectroscopy. J. Radiat. Res. Applied Sci., 7: 532-535.

Adeniji, A.E., O.O. Alatise and A.C. Nwanya, 2013. Radionuclide concentrations in some fruit juices produced and consumed in Lagos, Nigeria. Am. J. Environ. Prot., 2: 37-41.

Al-Hamidawi, A.A.A., 2015. Monitoring of 220Rn concentrations in buildings of Kufa Technical Institute, Iraq. Sci. Technol. Nucl. Installations, 2015: $1-5$.
Al-Jnaby, M.K.M., 2016. Radon concentration in drinking water sources of the University of Babylon/Iraq. J. Kerbala Univ., 14: 228-235.

Embaby, A.A., H.A. Yousef and H.A. Laken, 2016. Estimation of radon levels in groundwater samples from Graduate's Villages in West Nile Delta, Egypt using alpha track detectors. Intl. J. Phys. Res., 6: 1-10.

Hameed, T.K., 2015. Measurement of radon gas concentration in water and soil samples in AL-Najaf governorate by using nuclear track detector (CR-39). Baghdad Sci. J., 12: 603-610.

Hasan, A.K., K.H. Hatif and R.A. Hamid, 2017. Measurement of natural radioactivity of soil samples collected from government departments of districts, Qassim, Babylon, Iraq. Asian J. Res., 8: 1-18.

Jassim, A.Z., H.H. Al-Gazaly and A.A. Abojassim, 2016. Natural radioactivity levels in soil samples for some locations of Missan government, Iraq. J. Environ. Sci. Pollut. Res., 2: 39-41.

Obaid, S.S., D.K. Gaikwad and P.P. Pawar, 2015. Determination of natural radioactivity and hazard in some rock samples. Bionano Front., 8: 125-127.

Ravikumar, P. and R.K. Somashekar, 2014. Determination of the radiation dose due to radon ingestion and inhalation. Intl. J. Environ. Sci. Technol., 11: 493-508. 